\title{
ПРИМЕНЕНИЕ СБАЛАНСИРОВАННОЙ СИСТЕМЫ ПОКАЗАТЕЛЕЙ НА ТОРГОВЫХ ПРЕДПРИЯТИЯХ СТРОИТЕЛЬНОЙ ОТРАСЛИ
}

\author{
(C) 2021 Еремкина Ю. В.
}

студент магистратуры, направление «Экономика», программа «Учет, анализ, аудит» Финансовый Университет при Правительстве РФ, Россия, Москва

(c) 2021 Лялькова Е.Е.

кандидат экономических наук, доцент Департамента бизнес-аналитики Факультета налогов, аудита и бизнес-анализа Финансовый Университет при Правительстве РФ, Россия, Москва доцент кафедры «Бухгалтерского учета и налогообложения» ФГБОУ ВО РЭУ им. Плеханова, Россия, Москва

Необходимость применения системы сбалансированных показателей на торговых предприятиях строительной отрасли обусловлена сложившейся экономической ситуацией и мировыми тенденциями. Концепция системы сбалансированных показателей в торговой деятельности позволяет связать общую стратегию и цели предприятия с деятельностью всех подразделений.

Ключевые слова: стратегические цели, сбалансированная система показателей, торговая деятельность, стратегическая карта

Кризис 2020 года, связанный со всемирной пандемией, усилил и без того сильнейшую конкуренцию во всех отраслях. Важнейшими условиями для продолжения деятельности предприятий в условиях пандемии и удаленной работы является комплексное преобразование системы управления бизнесом. Только предприятия с гибкой системой управления, способностью быстро принимать решения и адаптироваться к сложившимся условиям, могут устоять перед кризисом подобного рода. Без анализа, который поможет оценить текущее состояние предприятия, обнаружить слабые и неэффективные сферы деятельности и выявления существенных характеристик, невозможно быстро преодолеть сложности и подстроиться к новым внешним условиям деятельности.

Сбалансированная система показателей эффективности (ССП) - это система измерения эффективности деятельности предприятия, основанная на видении и стратегии, которая отражает наиболее важные аспекты бизнеса. Сбалансированная система показателей основана на концепции декомпозиции целей для планирования операционной деятельности всех подразделений и сотрудников предприятия и контроля достижения цели.

Основной идеей разработки сбалансированной системы показателей является разработка стратегической карты, отражающей те пока- затели, которые позволят компании достичь поставленных целей. На основе выбранных показателей будут оперативно приниматься управленческие решения по их достижению.

Стратегическая карта состоит из четырех блоков: «Потенциал», «Внутренние процессы», «Клиенты и внешнее окружение» и «Финансы». Разрабатывая стратегическую карту, мы последовательно переходим от блока к блоку, отвечая на вопросы об основной цели предприятия; финансовых показателях, которые отражают эту цель; показателях, характеризующих работу с поставщиками и клиентами; о том, что поможет увеличить ценность для потребителей и улучшить работу с поставщиками; о необходимости улучшения программного обеспечения и квалификации персонала.

Каждый блок стратегической карты включает в себя несколько показателей - измерителей достижения цели. Показатели всегда сгруппированы, так как это наиболее удобный вид представления данных.

Выбор показателей осуществляется на основании выбранной стратегии, целей компании, требований ключевых стейкхолдеров. Показатели ограничены в количестве, чтобы менеджмент компании сфокусировался на наиболее приоритетных направлениях.

Разработаем стратегическую карту и систему показателей для малого торгового предприя- 
тия строительной отрасли.

Первый блок - «Финансы». Финансовые результаты помогают проанализировать текущее состояние предприятия, а также эффект от внедрения стратегии.

Для построения финансового уровня стратегической карты (таблица 1) необходимы организованные финансовый и управленческий учет, а также возможность сбора статистических данных по показателям.

Для достижения поставленных целей необходимо развивать надежность поставщиков, сокращать закупочные цены, увеличивать лояльность покупателей и ценность для них, улучшить рекламно-маркетинговый материал и развивать стратегические партнерства, а также улучшить квалификацию сотрудников и модернизировать оборудование.

Таким образом, при разработке системы показателей нельзя ограничиваться только финансовыми показателями.

Для разработки показателей следующего уровня необходимо изучить клиентов, внешнее окружение (поставщики, местное население, органы власти и пр.) и их требования, чтобы обеспечить подход к каждому сегменту. Целями данного уровня могут быть: увеличение доли рынка, захват нового сегмента рынка, повышение лояльности клиентов, развитие отношений с поставщиками (снижение количества опозданий и брака). Достижение целей на этом уровне должно способствовать улучшению финансовых показателей.

Исходя из целей, поставленных на финансовом уровне разработаем цели и показатели их достижения в сфере клиентов и внешнего окружения (таблица 2).

Мероприятия по достижению целевых показателей:

1. Проведение переговоров с поставщиками о необходимости строго соблюдать условия договора поставки. При необходимости пересмотреть условия.

2. Применение штрафных санкций к поставщикам, нарушающих условия договора.

3. Ведение списка поставщиков нарушителей, с целью ограничения их доступа к поставкам.

4. Ведение базы поставщиков и поиск альтернативных поставщиков.

5. Ежемесячный ввод в ассортимент позиций, привлекательных для покупателя и имеющие для него ценность (два по цене одного, подарок при покупке, накопительная скидка).

6. Поддержка используемых акций рекламной кампанией (местное радио, контекстная реклама в интернете, вывески на территории предприятия).

На следующем этапе «Внутренние процессы» главной целью является построение бизнеспроцессов, которое будет максимально удовлетворять потребности клиентов с минимальными издержками. Сокращение простоя оборудования, своевременность выполнения заказов и др.

Исходя из финансовых целей и требований стейкхолдеров разработаем цели и показатели их достижения для блока «Внутренние процессы» (таблица 3).

Увеличение количества качественной рекламы улучшит узнаваемость предприятия. На-

Таблицза 1. Показатели достижения цели блока «Финансы»

\begin{tabular}{|c|c|c|c|c|c|}
\hline \multicolumn{6}{|c|}{ Финансы } \\
\hline Цели & $\begin{array}{l}\text { Показатели до- } \\
\text { стижения цели }\end{array}$ & Формула & $\begin{array}{c}\text { Единица изме- } \\
\text { рения }\end{array}$ & $\begin{array}{c}\text { Целевое значе- } \\
\text { ние }\end{array}$ & $\begin{array}{c}\text { Фактическое } \\
\text { значение, } 2019 \text { г. }\end{array}$ \\
\hline $\begin{array}{c}\text { Увеличение } \\
\text { рентабельности } \\
\text { продаж на 10\% }\end{array}$ & $\begin{array}{c}\text { Рентабельность } \\
\text { продаж }\end{array}$ & $\begin{array}{l}\text { Отношение при- } \\
\text { были к выручке }\end{array}$ & $\%$ & 2,2 & $-8,2$ \\
\hline $\begin{array}{c}\text { Увеличение } \\
\text { уровня фондоот- } \\
\text { дачи на } 2 \text { руб. }\end{array}$ & Фондоотдача & $\begin{array}{c}\text { Отношение } \\
\text { выручки к сред- } \\
\text { негодовому зна- } \\
\text { чению основных } \\
\text { средств }\end{array}$ & руб. & 17,7 & 15,7 \\
\hline $\begin{array}{c}\text { Сокращение } \\
\text { доли затрат в } \\
\text { выручке до 85\% }\end{array}$ & $\begin{array}{c}\text { Доля затрат в } \\
\text { выручке }\end{array}$ & $\begin{array}{c}\text { Отношение } \\
\text { себестоимости } \\
\text { продаж к вы- } \\
\text { ручке } \\
\end{array}$ & $\%$ & $85 \%$ & $94 \%$ \\
\hline $\begin{array}{c}\text { Увеличение } \\
\text { объема продаж } \\
\text { на } 10 \%\end{array}$ & Выручка & Выручка & тыс.руб. & 69684 & 63349 \\
\hline
\end{tabular}


Таблица 2. Показатели достижения цели блока «Клиенты и внешнее окружение»

\begin{tabular}{|c|c|c|c|c|c|}
\hline \multicolumn{6}{|c|}{ Клиенты и внешнее окружение } \\
\hline Цели & $\begin{array}{l}\text { Показатели до- } \\
\text { стижения цели }\end{array}$ & Формула & $\begin{array}{c}\text { Единица изме- } \\
\text { рения }\end{array}$ & $\begin{array}{c}\text { Целевое значе- } \\
\text { ние }\end{array}$ & $\begin{array}{c}\text { Фактическое } \\
\text { значение, } 2019 \text { г. }\end{array}$ \\
\hline \multirow{2}{*}{$\begin{array}{c}\text { Развитие надеж- } \\
\text { ности постав- } \\
\text { щиков }\end{array}$} & $\begin{array}{c}\text { Уровень постав- } \\
\text { ки товаров несо- } \\
\text { ответствующего } \\
\text { качества }\end{array}$ & $\begin{array}{c}\text { Отношение } \\
\text { поставок несо- } \\
\text { ответствующего } \\
\text { качества к обще- } \\
\text { му количеству } \\
\text { поставок }\end{array}$ & $\%$ & 4 & 13 \\
\hline & $\begin{array}{c}\text { Частота опозда- } \\
\text { ний }\end{array}$ & $\begin{array}{c}\text { Отношение } \\
\text { зафиксирован- } \\
\text { ных поставок с } \\
\text { опозданием к } \\
\text { общему числу } \\
\text { поставок }\end{array}$ & $\%$ & 5 & 12 \\
\hline $\begin{array}{c}\text { Сокращение за- } \\
\text { купочных цен }\end{array}$ & $\begin{array}{c}\text { Закупочные } \\
\text { цены на метал- } \\
\text { лопрокат }\end{array}$ & $\begin{array}{c}\text { Отношение } \\
\text { закупочных цен } \\
\text { текущего перио- } \\
\text { да к закупочным } \\
\text { ценам прошлого } \\
\text { периода }\end{array}$ & $\%$ & 1,2 & 1,5 \\
\hline $\begin{array}{c}\text { Увеличение } \\
\text { ценности для } \\
\text { покупателей }\end{array}$ & $\begin{array}{c}\text { Количество } \\
\text { выгодных пред- } \\
\text { ложений для } \\
\text { покупателей }\end{array}$ & & Штук в месяц & 3 & 0 \\
\hline
\end{tabular}

Таблица 3. Показатели достижения цели блока «Внутренние процессы»

\begin{tabular}{|c|c|c|c|c|c|}
\hline \multicolumn{6}{|c|}{ Внутренние процессы } \\
\hline Цели & $\begin{array}{l}\text { Показатели до- } \\
\text { стижения цели }\end{array}$ & Формула & $\begin{array}{c}\text { Единица изме- } \\
\text { рения }\end{array}$ & $\begin{array}{c}\text { Целевое значе- } \\
\text { ние }\end{array}$ & $\begin{array}{c}\text { Фактическое } \\
\text { значение, } 2019 \text { г. }\end{array}$ \\
\hline \multirow{3}{*}{$\begin{array}{c}\text { Улучшение } \\
\text { рекламно- } \\
\text { маркетингового } \\
\text { материала }\end{array}$} & Интернет-сайт & & Шт. & 1 & 0 \\
\hline & $\begin{array}{c}\text { Цена за клик } \\
\text { в контекстной } \\
\text { рекламе }\end{array}$ & $\begin{array}{c}\text { Отношение сто- } \\
\text { имости разме- } \\
\text { щения к количе- } \\
\text { ству кликов }\end{array}$ & Руб. & до 10 & - \\
\hline & $\begin{array}{c}\text { Количество на- } \\
\text { ружной рекламы } \\
\text { в городе }\end{array}$ & & Шт. & 3 & 0 \\
\hline $\begin{array}{c}\text { Увеличение } \\
\text { стратегических } \\
\text { партнерств }\end{array}$ & $\begin{array}{c}\text { Количество } \\
\text { стратегических } \\
\text { партнерств }\end{array}$ & & Шт. & 5 & $\begin{array}{c}1 \text { поставщик } \\
\text { металлопроката, } \\
1 \text { п. кирпича, } 1 \text { п. } \\
\text { дерева }\end{array}$ \\
\hline
\end{tabular}

ружная реклама привлечет внимание местных жителей, контекстная реклама в интернете привлечет новых покупателей (дачники, недавно переехавшие и пр.). Интернет-сайт - необходимость для современных предприятий. Под стратегическим партнерством имеется в виду в первую очередь долгосрочное сотрудничество. Это взаимовыгодное сотрудничество, которое подразумевает более выгодные условия для обоих партнеров. Для предприятия предоставляются более выгодные цены, постоянное наличие необходимого товара, а предприятие в свою оче- редь обязуется выкупать обговоренные партии товара в оговоренные сроки.

Мероприятия по достижению целей:

1. Выделение бюджета на рекламу.

2. Проведение переговоров с потенциальными поставщиками о стратегическом партнерстве.

На четвертом уровне стратегической карты «Потенциал» рассматривается потенциал ресурсов предприятия: квалификация сотрудников, доступные технологии и информационное обеспечение. Показатели, которые характери- 
зуют этот уровень: обеспеченность сотрудников ИТ-системами, процент квалифицированных сотрудников и др. Потенциал предприятия - то, что обеспечит выполнение вышеуказанных целей. Установим цели и показатели их достижения (таблица 4).

Увеличение расходов на обучение ключевых сотрудников приведет к улучшению их эффективности в перспективе. На данный момент предлагается пройти обучение маркетологу, менеджеру по закупкам и бухгалтеру ответственному за ценообразование по улучшению их непосредственной деятельности. Введение в штат логиста позволит ускорить работу склада, доставки и закупочную деятельность. Это может быть как новый сотрудник, так и менеджер по закупкам прошедший повышение квалификации.

Реализация цели по модернизации оборудования и IT-систем улучшит производительность офисных компьютеров и специализированных программ. ERP-система - это интегрированная система управления предприятием, которая позволит контролировать и анализировать любую сферу деятельности: маркетинг, управление сбытом, управление персоналом, закупки, склад и пр. У ERP-систем есть преимущества, необходимые предприятию для устойчивого развития. Но у таких систем есть и недостатки, главным из которых в этом случае является высокая стоимость и довольно продолжительное внедрение и усвоение. Тем не менее, на предприятии уже используются продукты пакета 1С: Предприятие. Следовало бы расширить используемый пакет программ.

Без четырех блоков «Потенциал», «Внутренние процессы», «Клиенты и внешнее окружение» и «Финансы» невозможно внедрить сбалансированную систему показателей. Стратегическая карта наглядно показывает взаимосвязь глобальных целей компании с ее возможностями и потенциалом, взаимосвязь финансовой стабильности с клиентами и поставщиками.

Сбалансированная система показателей может использоваться как малыми, так и крупными предприятиями разных отраслей. Но существует ряд проблем при внедрении такой системы на российских предприятиях.

Система сбалансированных показателей в России в первую очередь, должна быть ориентирована на потребителей и клиентов, успешный опыт конкурентов и партнеров, так как долгосрочные цели и стратегии редко реализуются на предприятиях ввиду непредсказуемости и особенностей российского рынках.

Новшества на предприятиях зачастую сопровождаются увеличением бумажной работы, что снижает инициативность сотрудников.

Немаловажная проблема внедрения ССП на предприятиях является нежелание руководства предприятий менять стиль управления, нести затраты на внедрение и анализ такой системы, особенно это касается региональных бизнесов. Сбалансированная система показателей может использоваться как малыми, так и крупными предприятиями разных отраслей.

Тем не менее, учитывая особенности российского предпринимательства, сбалансированная система показателей применима на предприятиях, так как:

- система сбалансированных показателей расширяет возможности оценки финансового состояния за счет нефинансовых показателей;

- на малых и средних предприятиях удоб-

Таблица 4. Показатели достижения цели блока «Потенциал»

\begin{tabular}{|c|c|c|c|c|c|}
\hline \multicolumn{7}{|c|}{ Цели } & $\begin{array}{c}\text { Показатели достижения } \\
\text { цели }\end{array}$ & Формула & $\begin{array}{c}\text { Единица } \\
\text { измерения }\end{array}$ & $\begin{array}{c}\text { Целевое } \\
\text { значение }\end{array}$ & $\begin{array}{c}\text { Фактическое } \\
\text { значение, 2019 г. }\end{array}$ \\
\hline \multirow{2}{*}{$\begin{array}{c}\text { Повышение } \\
\text { квалификации } \\
\text { сотрудников }\end{array}$} & $\begin{array}{c}\text { Затраты на обучение } \\
\text { сотрудников }\end{array}$ & - & $\begin{array}{c}\text { Руб/на 1 со- } \\
\text { трудника }\end{array}$ & 10000 & 0 \\
\cline { 2 - 6 } & $\begin{array}{c}\text { Количество программ по } \\
\text { повышению квалификации }\end{array}$ & - & Шт. & 3 & 0 \\
\hline \multirow{2}{*}{$\begin{array}{c}\text { Модернизация в штат позиции: } \\
\text { оборудования } \\
\text { и ІТ-систем }\end{array}$} & $\begin{array}{c}\text { Индекс производительно- } \\
\text { сти компьютера }\end{array}$ & - & Шт. & 1 & 0 \\
\cline { 2 - 6 } & $\begin{array}{c}\text { Затраты на модернизацию } \\
\text { имеющегося оборудования }\end{array}$ & - & Шт. & 1 & 0 \\
\hline
\end{tabular}


но применять систему показателей ввиду компактности системы и ограниченного количества пользователей;

- данные показателей наиболее объективны и меньше поддаются фальсификации.

Таким образом, финансовая стабильность предприятия зависит не только от финансовых, но и нефинансовых факторов. Чтобы полностью описать состояние предприятия недостаточно только финансовых показателей. Сбалансированная система показателей помогает оценить влияние различных факторов на благосостояние всего предприятия. Идея взаимозависимости финансовых и нефинансовых факторов в системе показателей перекликается с идеями бизнесанализа.

\section{Библиографический список}

1. Бариленко, В.И. Методология бизнес-анализа: учебное пособие / Бариленко В.И.- Москва: КноРус, 2019.190 с. - (магистратура). - ISBN 978-5-406-07060-4.

2. Челышева Э.А., Шульженко В.А.Сбалансированная система показателей как инстурмент совершенствования системы финансового планирования на предприятии // Заметки ученого. 2016. № 8(14) стр. 61-67 (URL: https://www.elibrary.ru/item.asp?id=28868571\& дата обращения:16.12.2020) 